\title{
Research on the Status of Job Burnout Existing Among College PE Teacher in Hubei
}

\author{
Yuzhong LIU \& Liang LIU* \\ Hubei Engineering University, Hubei, China
}

\begin{abstract}
Job burnout is a state of physical and emotion fatigue caused by the rapid tempo of life in modern society .it main exists among of people under intense stress such as the police, doctors and teacher. College PE teacher are involved not only in strenuous physical work and scientific research, but also in pressure from family, school and other relationship. in view of this, the paper conduct a systematic research on the job burnout existing among the College PE teacher in Hubei, presents the problem, and advances countermeasures and suggestion.
\end{abstract}

KEYWORD: PE teacher; burnout; motion fatigue; dimensions

\section{INTRODUCTION}

Accompanying with the fast development of china's social and economy and increasing awareness of competition, and pressure faced by Chinese people is on the rise as well. College beseecher, as an important occupation, requires teachers to complete their work with great effort. Beseechers are under intense stress since they are endowed with expectation and responsibility by the whole common -ity and undertake great task of teaching concerned with the destiny of the nation, in addition, various education reforms put heavier burden on them without being notice. Should the pressure not be eased or released in a period of time, they may get tired of the work, or other, suffer called, job burnout. In the last two or three decades, ob burnout has already been a research hotpot in the filed of wrester organization be havioristic and human resource management. Recently, it has become one of the important topics at US.HR Conference. College PE teacher, engaged in peculiar career, are facing a higher risk being attacked by exhaustion. At present, there are large among of PE teacher in numerous polytechnic school, college and university in Hubei province. the research on the job burnout existing among them and the factors leading to the phenomenon will promote their physical and mental development.

\section{THE OBJECTS AND METHODS OF THE RESEARCH}

\subsection{The objects of the research}

A random sample of $360 \mathrm{PE}$ teachers in 18 represent ative college and university such as Physical Education School of Huazhong University, Wuhan Sports University, Hubei University, JiangHan University, China Three Gorges University, XiangFan University, and HuangGang University.

\subsection{The method of the research}

Literature study, experts interviewing, questionnaire surveying, mathematic statistics

\section{RESULT AND ANALYSIS}

\subsection{The status of job burnout existing among college PE teachers in Hubei}

Statistic in table shows that job burnout existing among college PE teachers in Hubei thought it's not serious. Bared the three analysis of the three dimensi onnnns in MBI-ES, it presents that the core indicator of job burnout - emotion exhausted standout, with the average of 3.1584 ,exceeding 3, which indicates quite a few teachers are struggling with emotion exhaustion. The average of reduced personal accompli sheen is 2.8365, close to 3and the depersonalizations above 2.5.these figures demonstrate that the job burnout among the PE teachers in Hubei continues to worsen. 


\subsection{The developmental feature of job burnout of college PE teachers in Hubei}

\subsubsection{The feature sex and teaching age in the job burnout}

Sex and teaching age are closely related to the job burnout among college PE teachers. teachers with different sex and working age differ from each other on the tendency of the three dimension .statistic in table two illustrate that the male PE teachers have a higher rate of emotional exhaustion and reduce personal accomplishment and a lower rate of depersonalization than the female teachers. On the whole, the male college PE teachers in Hubei have a higher job burnout than the female teachers. This indicates that the male bear more outside pressure than the female do. Teachers within 5 teaching age suffer fewer job burnout problems, while teachers within 10-15 suffer more. Those within 10-20 in particular. The reason is that the middle age teachers face pressure from family and work, the monotonous teaching and scientific research.[1]

\subsubsection{The feature of academic qualification and professional title in the job burnout}

Academic qualification and professional title, as the important indicators of evaluating a teacher's allround ability, are highly valued by many college teachers. Both of them represent the lever of the knowledge and cultural accomplishment. Professional title, in particular, is the good measure of salaries as well as teaching and scientific research capability; his on the other hand makes a negative impact on the college PE teachers. They not only undertake heavily technical and theoretical teaching but also further their study, apply for subjects and do researches to obtain academic qualification and professional titles. There are source of the increasing pressure. From the analysis, it can be seen that academic qualification and professional title are closely related to the job burnout. Statistics in Table 3 indicate the emotion exhaustion and reduced personal accomplishment are very common among the college PE teachers with a bachelor's degree. They suffer more job burnout than the teacher with master's or doctor's degree do. Teachers with a doctor's degree have fewer problems than those with a bachelor's master's degree on the three dimensions. as to the professional title, it is analyzed that the PE teachers with a little of Associated Professor have serious job burnout symptom while those with the tittles of Assistant Professor have fewer problem than other teachers on the three dimensions since they are mostly new graduates and have energy and enthusiasm.[2] The professors, with the increasing age and increasing energy, are more likely to suffer the emotion exhaustion than the assistants and lectures.

\subsection{The analysis of the cause of the job burnout among the PE teachers in Hubei.}

\subsubsection{The disciplines status of PE teaching}

The disciplines status of consisting of professional status ,economy position and professional prestige, directly influences the mental state of an individual teacher, many PE teacher are so confused with their roles that they cannot have a sufficient understanding of their own position and responsibility. This is caused by the fact that the school cannot provide a clear role orientation for the PE teacher. the phenomenon that the discipline status of PE teaching is a disadvantage exists in college and university of Hubei as well.[3] the statistics show that $82.6 \%$ of the PE teacher consider PE teaching borderline subject overlooked in school, $79 \%$ of them think there is income gap compared with teachers of others subject, with the ratio of prize at the end of the subject, and $88 \%$ think the professional prestige is lower than others teachers. Based on the above figures, it's known that the low disciplines status of PE teaching is one of the important factors causing the job burnout among the PE teachers in Hubei.

\subsubsection{The living environment of college PE teacher in Hubei}

Hubei has been the economical and culture center in mid-china where the high commodity, housing price and soaring consumption to the extremely poor salary. The intense competitive pressure and rapid tempo of life is vividly reflected by the picture seen everywhere that the students or office workers also need cope with the family and the interpersonal relationships. The high pressure and physical-andmental exhaustion are far beyond our imagination. From the above analysis, it can be seen that the living environment is the important reason causing the job burnout among the college PE teacher in Hubei.

\subsubsection{Personal factor of the college PE teacher in Hubei}

One of reason that some people tend to suffer job burnout while not can be traced back to individual the main aspect is is the character, on which people differ from each other. Some disposition possessors are easily attacked by job burnout. Related researches show that the teacher by the outside are more likely to suffer job burnout than other those self controlled. Another aspect is the individual will and devotion to duty.[4] A large among of college PE teacher don't possess the steadiness of work ideology, firm and high devotion to duty so that they cannot realize the lofty value of teaching and the far-reaching effect for students, let alone the high devotion to scientific research. They 
view PE teaching as Yamane, where no fame and fortune can be obtained. Although for the PE teachers are betters than before, it contrasts unfavorably with high-grade material please .some teacher cannot bear the poor salaries so that they palter with the teaching and scientific research with bade attitude. After a long time, the mental exhausted is unavoidable, and the job burnout thus takes shapes.

\section{CONCLUSION AND SUGGESTIONS}

\subsection{Conclusion}

4.1.1 The feature of the job burnout among the college PE teachers is as follows. First, teachers with different sex have different performance. The male teachers are more likely to suffer job burnout than the female teachers do secondly; there are differences in teaching age. Teacher within 5 teaching age have fewer job burnout symptoms while teachers within 10-15 have obvious one thirdly, there is differently in academic qualification. Teacher with a bachelor's degree suffer more than those with a maser's or doctor's degree. Fourthly, the difference exists in professional title. Teacher who have the title of associated professor or professor suffer the job burnout severely while teachers with the tittles of assistant professor or lecture have fewer problems, of which the assistant professor or lecturer have fewer problems, of which the assistant professors have the fewest.

4.1.2 There are various reasons causing the job burnout among the college PE teachers in Hubei. Firstly, the effect of teaching hysteretic and the discipline status of PE teaching are at disadvantage among all subjects secondly, the working environment of the PE teachers is monotonous, meanwhile, living in Hubei needs to bear intense competitive pressure and rapid tempo of life. Thirdly character is one of the important reasons result the job burnout. Statistic shows that the teacher's controlled by the outside are more likely to feel job burnout than those who are self-controlled. Fourthly, many PE teachers have been tortured by injuries.

\section{2 suggestions}

4.2.1 The local government and school need to attach more important to the job to the job burnout existing among the college PE teachers in Hubei and realize the important role of the PE teaching plains. Meanwhile, they should establish the humanoriented management policy, guard against the worsening of job burnout and strengthen the humanity solicitude.

4.2.2 The real problem such as the housing shortages and poor salaries should have be solved in accordance with the development in different areas of Hubei. Besides, pleasure environment and sport center should be developed for the PE teacher so as to enrich their free time and increasing exchanges.

4.2.3 The professional evaluation of the college PE teachers ought to strictly examine on the principle of fairness and justice, avoiding the conflict between teachers and discontent with the school.

4.2.4 The PE teachers should be encouraged further their study both abs home and abroad, improve their academic lever, the teaching competence as well as the individual accomplishment.

4.2.5 The education of value and outlook on life should be strengthened so as to help the teachers build up the correct ones and improved the spirit of devotion and dedication.

\section{REFERENCES}

[1] Lin Ningbo, Xing Ying. Analysis on Present Situation Of Job Burnout In P.E Teacher Of General Colleges And Universities In Henan Province. Journal of Anhui Sports Science. 2007 (1):56-57.

[2] ZHANG Jie. Survey of occupational burnout of physical education teachers in common institutes of higher learning in Henan Province. Journal of Physical Education. 2007(2):83-84.

[3] JING Ling. College P.E.teachers' occupational tiredness and its influences-A survey in Wuhan. Journal of Wuhan Institute of Physical Education. 2008(11):103-104.

[4] QIU Xiang. Improving Material Remuneration and establishing Psychological Maintenance System Studying on P.E Teachers' Relieving Way of Job-burn in University. Journal of Nanjing Institute of Physical Education (Natural Science). 2008(1):46-47. 